Богуслаев В. А. ${ }^{1}$, Кочюба В. Ю. ${ }^{1}$, Павленко Д. В. ${ }^{2}$

1 АО «Мотор Сич». Украина, г. Запорожье

2 Запорожский национальный технический университет. Украина, г. Запорожье

\title{
МОДЕРНИЗАЦИЯ ПРЕССОВОГО ОБОРУДОВАНИЯ ДЛЯ РЕАЛИЗАЦИИ ТЕХНОЛОГИЙ ИНТЕНСИВНОЙ ПЛАСТИЧЕСКОЙ ДЕФОРМАЦИИ СПЛАВОВ ДЛЯ АВИАЦИОННОЙ ТЕХНИКИ
}

\begin{abstract}
Выполнен анализ особенностей интенсивной пластииеской деформации металлов и сплавов методом винтовой экструзии. Рассмотрены основные требования $к$ прессовому оборудованию для реализации технологии интенсивной пластической деформации винтовой экструзией. Разработаны основные принципы и пути модернизации гидравлических прессов для реализации данной технологии в условиях серийного производства. Решены задачи, связанные с модернизацией систем управления прессом, гидравлической и электрической систем, а также мероприятий по обеспечению безопасности выполнения работ. На примере гидравлического пресса П-315 показаны пути модернизации гидравлических прессов, позволяющие выполнять деформацию заготовок из широкого спектра титановых и железоникелевых сплавов винтовой экструзией на опытнопромышленной установке. [dx.doi.org/10.29010/081.1]
\end{abstract}

Ключевые слова: гидравлический пресс; модернизация; интенсивная пластическая деформация; винтовая экструзия; гидравлическая система; электрическая система; автоматизация.

Введение

Благодаря аномально высокому уровню физических, механических и специальных свойств, которыми обладают металлы и их сплавы в наноструктурированном состоянии, технологии интенсивной пластической деформации (ИПД) находят все более широкое применение в различных областях техники $[1,2,3,4]$. В настоящее время в мире активно развиваются несколько десятков различных методов ИПД [5, 6, 7]. Однако, с точки зрения авиационного и общего машиностроения, практический интерес представляют методы, позволяющие получать объемные заготовки в наноструктурированном состоянии достаточно большого размера. Среди них следует отметить равноканальное угловое прессование [7, 8], винтовую экструзию [9], всестороннюю ковку [10] и реверсивный сдвиг [11]. В работе [12] было показано, что на основе указанных методов ИПД могут быть построены перспективные комплексные технологические процессы для получения заготовок деталей авиационных двигателей из различных сплавов с высоким уровнем свойств и субмикрокристаллической структурой. В основе комплексных технологий ИПД лежат методы, позволяющие обеспечивать в очаговой зоне деформации высокий уровень гидростатического давления. Это позволяет обрабатывать материалы, обладающие низкой пластичностью, напри- мер, спечённые сплавы, сплавы на основе алюминидов титана, не допуская их разрушения. Также такие методы позволяют успешно обрабатывать высокопрочные сплавы на железоникелевой основе типа ЭП718, ЭИ 698 и другие [13].

На предприятии АО "МОТОР СИЧ", для получения заготовок лопаток компрессора современных газотурбинных двигателей, в качестве метода для чернового этапа комплексной технологии ИПД принята деформация заготовок винтовой экструзией, разработанная профессором Бейгельзимером Я.Е. [9]. Данный способ в сравнении с альтернативными способами деформации отличается тем, что в зоне деформации заготовки в процессе обработки создается напряженно-деформированное состояние, близкое к всестороннему сжатию [14]. При этом, путем изменения величины противодавления, прикладываемого к переднему торцу заготовки, имеется возможность выполнять обработку как в условиях, близких к всестороннему сжатию, так и при относительно низком уровне гидростатического давления. Широкие технологические возможности винтовой экструзии позволяют существенно расширить круг обрабатываемых материалов, включая композиционные материалы [15] и некомпактные сплавы [16], в сравнении с альтернативными способами. Главное преимущество этого процесса перед другими основными методами ИПд заключается в формировании мультимасштабных 
вихревых движений (подобных турбулентности в жидкостях), инициируемых в обрабатываемом материале из-за того, что деформация осуществляется инструментом специальной формы [9, 17, 18]. Наличие вихрей в заготовке позволяет, в отличие от альтернативных методов ИПд, обеспечивать высокую степень гомогенности химического состава сплава. Получаемые при помощи винтовой экструзии заготовки также обладают высокой технологической пластичностью [19], что позволяет сократить затраты на технологический процесс изготовления из них деталей ГТД.

Несмотря на очевидные преимущества в сравнении с аналогами, винтовая экструзия имеет и ряд недостатков, ограничивающих ее применение. Основными из них являются невозможность обработки длинномерных заготовок, а также сложность и относительно высокая стоимость технологического оборудования. При этом сложность опытно-промышленной установки для деформации винтовой экструзией [20] усугубляется рядом специфических требований, предъявляемых к прессовому оборудованию, на котором она монтируется. В работе [21] было показано, что нарушение режимных параметров процесса ИПд заготовок на каждом из циклов деформации, а также нерациональная геометрия канала винтовой матрицы могут приводить к разрушению заготовок и элементов технологической оснастки (рис. 1).
ИПД сплавов, применяющихся в авиационной технике, методом винтовой экструзии. Для ее достижения были решены задачи, связанные с анализом требований к прессовому оборудованию, модернизацией системы управления прессом, гидравлической и электрической систем.

\section{Результаты исследований}

В зависимости от размеров сечения заготовки и ее материала, усилие пресса для реализации деформации винтовой экструзией может варьироваться от 63 до 630 МН. При этом, учитывая большие степени деформации в канале винтовой матрицы, а также ее изнашивание, обработку необходимо выполнять при скоростях, соответствующих диапазону работ гидравлических прессов. Независимо от усилия, развиваемого главным цилиндром пресса, учитывая особенности процесса ИПД винтовой экструзией и конструкции специальной опытно-промышленной установки [20], он должен обладать возможностью контролируемого перемещения на всей траектории рабочего и холостого ходов. Он также должен обладать возможностью контроля и регулирования усилия прессования, иметь функцию аварийного отключения при увеличении усилия, что позволит исключить разрушение установки для винтовой экструзии в случае заклинивания или "закусывания" в процессе

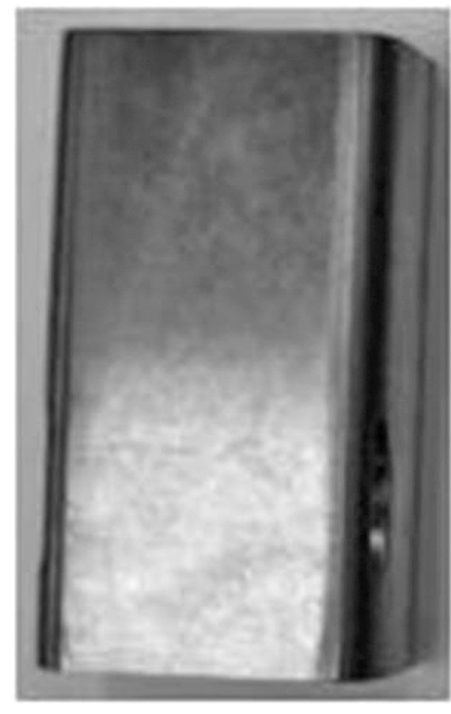

a

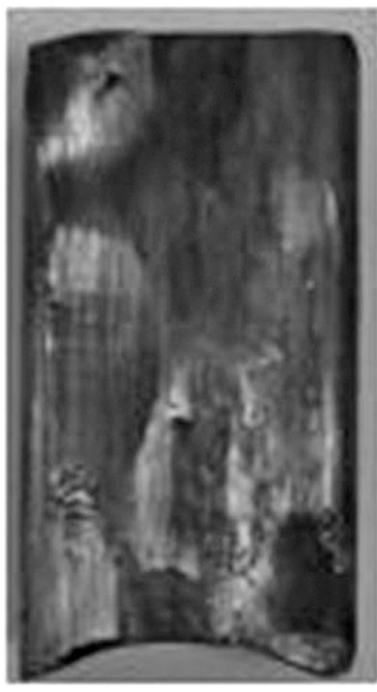

б

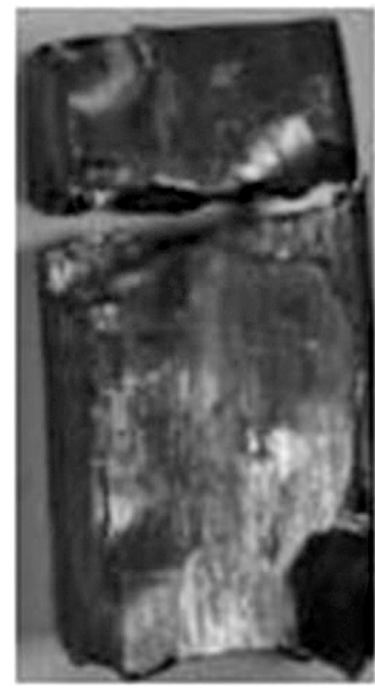

Pис. 1. Заготовка из сплава ВТ1-0 до ИПД винтовой экструзией (а), после деформации (б) и разрушенная в процессе деформации (в) [21]

\section{Постановка задачи}

Целью настоящей работы являлась разработка основных принципов и путей модернизации гидравлических прессов для реализации технологии деформации основной или фальш-заготовок. Немаловажным аспектом применяемого прессового оборудования является также наличие обратного цилиндра - выталкивателя (маркеты), позволяющего реализовать деформацию с противодав- 


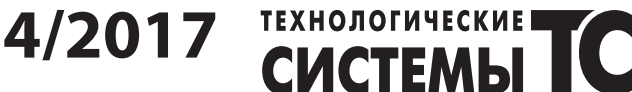

лением. При этом к нему предъявляются аналогичные с основным гидроцилиндром требования по контролю усилия и скорости перемещения. Применяемый пресс также должен обеспечивать независимое регулирование режимами работы основного гидроцилиндра и цилиндра выталкивателя. Для исключения случаев разрушения заготовок из титановых сплавов вследствие возникновения больших градиентов температур в образце по причине их низкой теплопроводности, пресс должен иметь возможность обеспечивать достаточно высокие скорости перемещения, что обеспечивается большим расходом гидравлической жидкости, подаваемой гидравлическим приводом. Размеры рабочей зоны пресса, а также рабочие и холостые ходы ползуна и выталкивателя должны позволять реализовывать цикл деформации винтовой экструзией, связанный с удалением фальшзаготовки и деформацией пакета, состоящего из двух фальш и одной основной заготовок [9]. Для обеспечения требований правил техники безопасности он должен предусматривать защиту от попадания в рабочую зону посторонних объектов, систему аварийной блокировки и фиксации ползуна в верхнем положении.

В настоящее время ряд зарубежных фирм серийно выпускают гидравлические прессы, хоро-

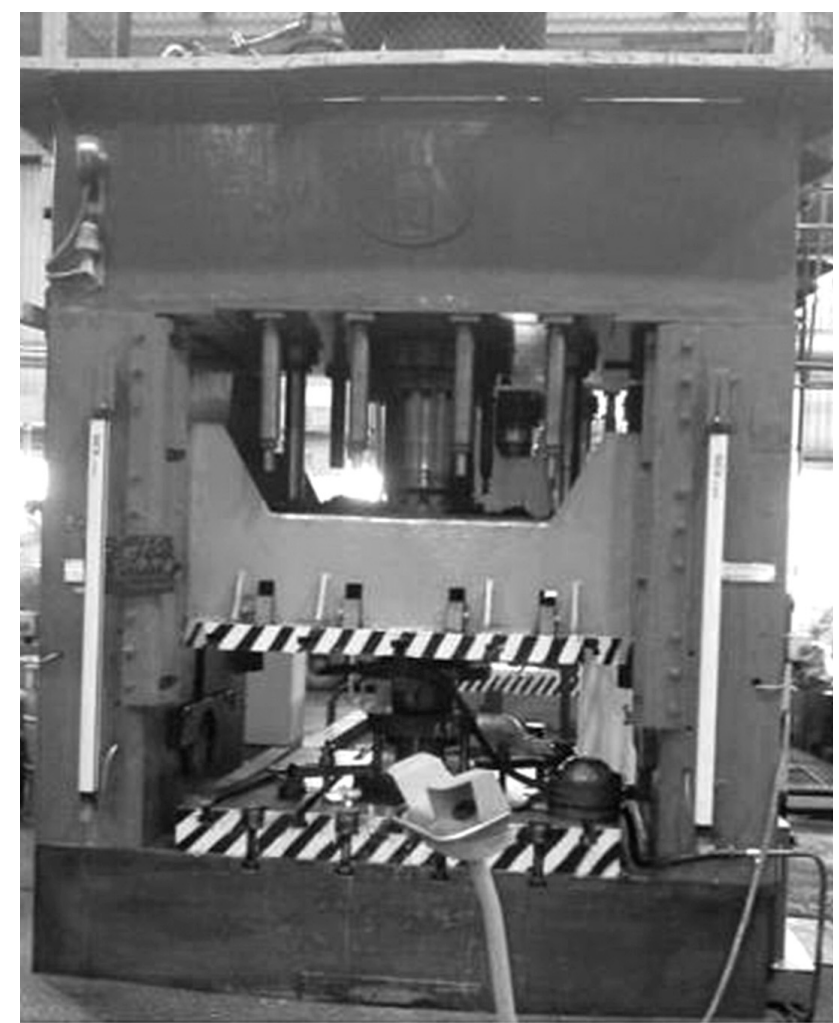

a шо удовлетворяющие требованиям, предъявляемым к ним для реализации ИПД винтовой экструзией. Однако, учитывая стоимость прессового оборудования и наличие большого парка прессов предыдущего поколения, на предприятии АО "МОТОР СИЧ" пошли по пути глубокой модернизации гидравлических прессов моделей П-313. П-315, П-3434 и аналогичных. Конструктивно указанные прессы позволяют реализовывать деформацию методом винтовой экструзии. Однако, в заводском исполнении они не отвечают ряду указанных выше требований и, как следствие, не могут эффективно применяться для реализации технологии ИПД металлов методом винтовой экструзии.

Для реализации технологии ИПД среднегабаритных заготовок из железоникелевых и титановых сплавов, учитывая их физические и механические свойства, на АО "МОТОР СИЧ" были модернизированы гидравлические прессы модели П-315 (рис 2, а).

Для реализации техничных характеристик пресса (табл. 1), удовлетворяющих условиям работы опытно-промышленной установки винтовой экструзии (рис. 2, б), модернизации подверглись гидравлическая и электрические части, включая автоматизацию путем оснащения системой числового программного управления.

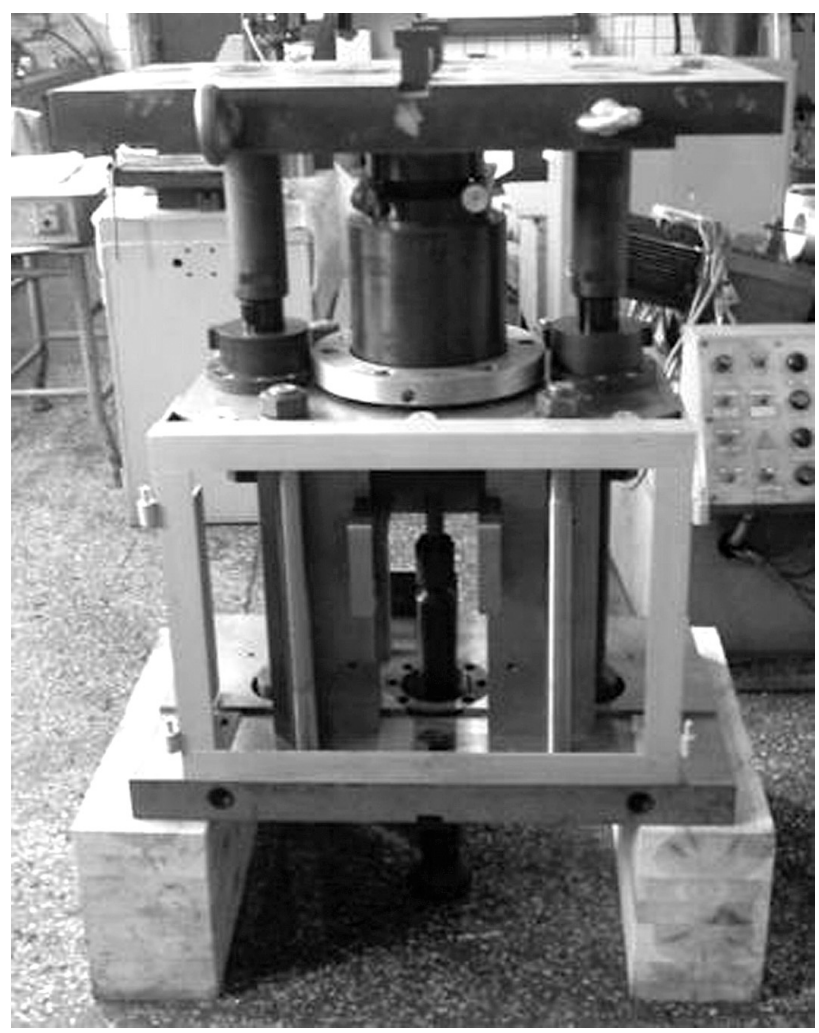

б

Рис. 2. Общий вид модернизированного гидравлического пресса П-315 (а) и монтируемой на нем опытнопромышленной установки для ИПД винтовой экструзией (б) 


\section{Технические характеристики модернизированного пресса П-315}

\begin{tabular}{|c|c|c|}
\hline $\begin{array}{l}\text { № } \\
\Pi \backslash \Pi\end{array}$ & Параметр & Значение \\
\hline 1 & Номинальное усилие на ползуне & $6300 \mathrm{\kappa H}$ \\
\hline 2 & Номинальное усилие на гидроподушке & $2500 \kappa \mathrm{H}$ \\
\hline 3 & Усилие возвратного хода ползуна & $200 \mathrm{\kappa H}$ \\
\hline 4 & Усилие прижимной плиты выталкивателя, регулируемое & $10 \ldots .2500 \kappa \mathrm{H}$ \\
\hline 5 & Наибольший ход ползуна & $730 \mathrm{мм}$ \\
\hline 6 & Наибольший ход гидроподушки & 350 мм \\
\hline 7 & Расстояние наибольшее между ползуном и плитой & $1400 \mathrm{MM}$ \\
\hline 8 & Скорость опускания ползуна, холостой ход & $200 \mathrm{мм} /$ сек \\
\hline 9 & Скорость прессования, регулированная & $10 \ldots 20$ мм/сек \\
\hline 10 & Скорость подъема ползуна, регулированная & $50 \ldots 120$ мм/сек \\
\hline 11 & Скорость выталкивателя вверх & $10 \ldots 50$ мм $/$ сек \\
\hline 12 & Скорость выталкивателя вниз & 200 мм/сек \\
\hline 13 & $\begin{array}{l}\text { Кол-во рабочих цилиндров } \\
\text { два главных усилием } 6500 \text { кН, } \\
\text { один цилиндр ускоренного хода ползуна }\end{array}$ & Зшт \\
\hline 14 & Максимальное давление жидкости в гидросистеме & $20 \mathrm{MПа}$ \\
\hline 15 & $\begin{array}{l}\text { Производительность гидронасоса, автоматически } \\
\text { регулируемая }\end{array}$ & $50 \ldots 200$ л/мин \\
\hline 16 & Система охлаждения масла & водяная \\
\hline 17 & Режимы работы гидропресса & $\begin{array}{l}\text { наладка, полуавтоматический, } \\
\text { автоматический }\end{array}$ \\
\hline
\end{tabular}

В гидравлической части пресса, наряду с заменой физически изношенного гидрооборудования насоса главного привода, гидропанели и гидрораспределителей, проведена модернизация системы охлаждения масла и его фильтрации, что позволило обеспечить 9-11 класс чистоты согласно ГОСТ 17216-71. Разработанный новый гидравлический привод пресса

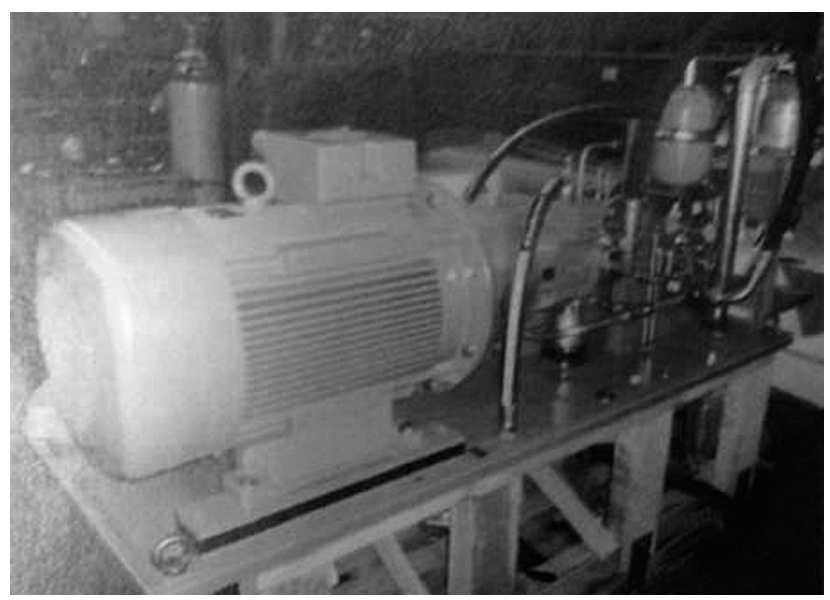

Рис. 3. Общий вид гидравлического привода модернизированного пресса П-315 имеет ряд принципиальных отличий от серийного, используемого на прессах данного типа (рис. 3).

Гидропривод выполнен в виде единого модуля, смонтированного на баке с рабочей жидкостью. Привод не имеет собственных цепей управления и защиты элементов электрического оборудования и использует соответствующие цепи пресса. Рабочее давление гидравлической жидкости составляет $2 . . .32$ МПа и дистанционно регулируется при помощи электромагнитного клапана. Максимальный расход гидравлической жидкости составляет 250 дм $^{3} /$ мин, что позволяет реализовывать ускоренный, в сравнении с серийным гидравлическим приводом пресса, рабочий и холостой ходы ползуна и выталкивателя. Фильтрование и охлаждение рабочей жидкости обеспечивается самостоятельным напорным контуром. Для предупреждения засорения фильтров, а также контроля температурного режима работы гидравлического привода он оснащен контрольно-измерительной аппаратурой, связанной с центральным блоком управления пресса.

Модернизация электрической части пресса и оснащение его современной системой числового 
программного управления являлась важной составляющей адаптации пресса для работы с разработанной установкой ИПД, что связано с необходимостью ее эксплуатации в циклическом режиме с заданными на каждом из участков цикла параметрами. Для этого, наряду с заменой электрооборудования пресса на современное, модернизация электрической части предусматривала разработку автоматизированной системы управления, гидрораспределителя с автоматической настройкой усилия прессования и скоростью перемещения ползуна и выталкивателя.

Система управления электрической частью модернизированного пресса построена на контроллере фирмы Siemens. Программный комплекс позволяет управлять работой пресса посредством панели оператора (рис. 4, а), являющейся программируемым устройством, предназначенным для выполнения операций изменения и ввода режимных параметров прессования. После ввода, они сохраняются в постоянно запоминающем устройстве контроллера и могут впоследствии быть воспроизведены в автоматическом режиме. Сенсорный экран панели оператора (рис. 4, б) обеспечивает простой доступ оператора к различным меню управления прессом.

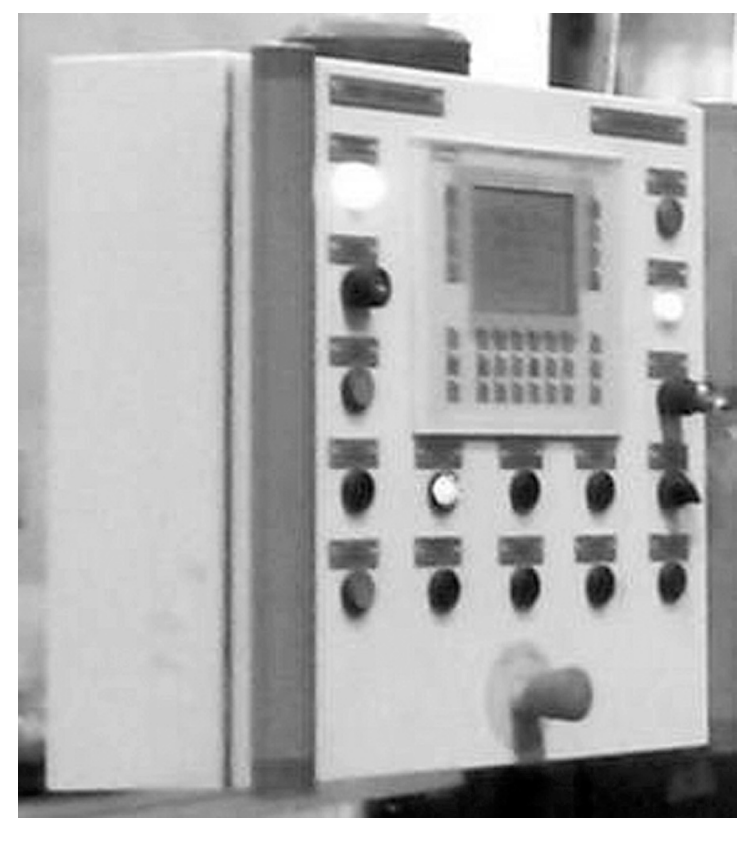

a ратором заранее запрограммированных циклов деформации в зависимости от обрабатываемого материала. Возможность работы пресса в автоматическом цикле позволяет реализовывать деформацию винтовой экструзией с контролируемыми перемещениями и усилием ползуна и выталкивателя, что исключает разрушение заготовки и технологической оснастки. Кроме контроля абсолютных и относительных значений перемещения система позволяет задавать габаритные размеры оснастки, что исключает возможность их столкновения.

Учитывая, что технология деформации винтовой экструзией предусматривает применение фальш-заготовок, а также наличие на винтовой матрице зон с высокими градиентами деформаций заготовки, система управления прессом предусматривает ступенчатое регулирование параметров деформации. Рабочий ход ползуна и выталкивателя разделены на 5 зон, в которых допускается независимое регулирование основных параметров. На каждом из пяти участков имеется возможность задания положения, скорости перемещения, ускорения и усилия независимо как ползуна, так и выталкивателя. В процессе работы на экране панели оператора отображаются запрограммированные

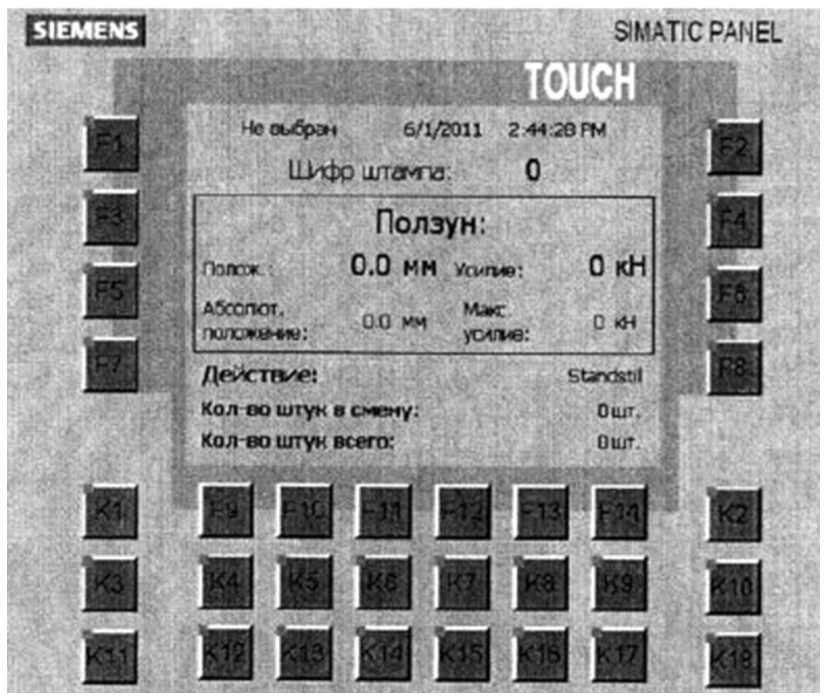

б

Рис. 4. Общий вил (а) и рабочий экран (б) панели оператора модернизированного пресса П-315

Применение автоматизированной системы управления позволило реализовать в программируемом цикле управление давлением и скоростью прессования, положением ползуна и цилиндра выталкивателя, а также сигнализацию основных отказов. Также имеется возможность выбора опе- значения параметров и их фактические значения. Предусмотрен также режим задания предельных перемещений выталкивателя и ползуна, их начальных положений, контроль выбега, а также режим отображения статистики работы и отказов пресса. Выталкиватель позволяет работать в таких режи- 
мах как прижим, выталкиватель, ограниченное движение, а также режим ручного управления. Для исключения повреждений оснастки предусмотрен ввод лимитирующих значений, что позволяет не допустить параметров на каждом из участков перемещения, которые могут привести к аварийным ситуациям.

В процессе модернизации особое внимание было уделено также повышению уровня безопасности выполнения работ на прессе. Для этого было предусмотрено двуручное включение хода ползуна; фотозащита рабочей зоны, фиксация ползуна в верхнем положении при наладочных работах с блокировкой; предохранительные устройства для случая перегрузки усилия прессования на ползуне и выталкивателе и ряд других мероприятий.

\section{Выводы}

Таким образом, обоснованные и реализованные мероприятия по модернизации гидравлических прессов на АО "МОТОР СИЧ" позволили при относительно низких капитальных вложениях реализовать процесс интенсивной пластической деформации сплавов для авиационной техники методом винтовой экструзии. Автоматизация выполнения основных операций позволила обеспечить высокое качество деформируемых заготовок, исключить их разрушение и повысить уровень безопасности выполнения работ.

\section{Литература}

[1] Roberto B. Using Severe Plastic Deformation for the Processing of Advanced Engineering Materials / B. Roberto, I. Figueiredo, G. Terence, I. Angdoni // Materials Transactions. - 2009. Vol. 50, No. 7 P. 16131619.

[2] Greger M. Mechanical properties of ultra-fine in titanium / M. Greger, M. Widomska, L. Kander // Journal of Achievement sin Materials and Manufacturing Engineering. - 2010. - Vol. 40, ISSUE 1, P. 33-40.

[3] Valiev R.Z. A Paradox of Severe Plastic Deformation in Metals / R.Z. Valiev, I.V. Aleksandrov // Doklad y Physics. - 2001. Vol. 46, No. 9, - P. 633-635.

[4] Verlinden B. Sever plastic deformation of metals / B. Verlinden // Metalurgija-Journal of metallurgy. 2005. - Vol.11 P.165-182.

[5] Wang Cheng Peng Review on modified and novel techniques of severe plastic deformation / W. Cheng Peng, L. Fu Guo, W. Lei, Q. HuiJuan // Technological Sciences. - 2012. Vol. 55, No. 9. - P. 2377-2390.

[6] Колесников А.Г. Анализ способов измельчения структуры при получении металлических конструкционных материалов / А.Г. Колесников, А.С. Шинкарев. // Наука и Образование. МГТУ им. Н.Э. Баумана. Электрон. Журнал. - 2014. - № 11. - С. 34-44.
[7] Valiev R.Z. Producing Bulk Ultrafine-Grained Materials by Severe Plastic Deformation: Ten Years Later / R.Z. Valiev, Y. Estrin, Z. Horita at at. // Journal of the materials. - 2016. - Vol. 68, No. 4. - P. 12161226.

[8] Sabirov I. Nanostructure aluminum alloys produced by severe plastic deformation: new horizon sidevelopment / I. Sabirov, M.Yu. Murashkin, R.Z. Valiev // Materials Science \& Engineering. - 2013. - Vol. 560. - P. 1-24.

[9] Beygelzimer Y Twist Extrusion as a Potent Tool for Obtaining Advanced Engineering Materials: A Review / Y. Beygelzimer, R.Kulagin, Y. Estrin, at. al // Advanced engineering materials. - 2017. - Vol. 19, Issue 8. - P 1600873.

[10] Сергеев С.Н. Влияние всесторонней изотермической ковки на структуру и свойства низкоуглеродистой стали 12ГБА / С.Н. Сергеев, И.М. Сафаров, А.В. Корзников и др. // Письма о материалах. 2012. - T. 2 - C. 117-120.

[11] Тарасов А.Ф Развитие комбинированных методов обработки с использованием интенсивного пластического деформирования / А.Ф. Тарасов, А.В. Алтухов, О. С. Литвин // Пластична деформація металів. 2017. - C. 282-288.

[12] Павленко Д.В. Методология обработки давлением спеченных сплавов при изготовлении деталей газотурбинных двигателей /Д.В. Павленко // Вестник двигателестроения. - 2017. - №1. - С. 83-92.

[13] Павленко Д.В. Анализ условий формирования субмикрокристаллической структуры в железоникелевых сплавах винтовой экструзией / Д.В. Павленко, Д.В. Ткач, В.Ю. Коцюба, Я.Е. Бейгельзимер // Металловедение и термическая обработка металлов. - 2017. - №5. - С. 8-14.

[14] Михайлов О.В. Моделирование процесса винтовой экструзии порошковых заготовок / О.В. Михайлов, Я.Е. Бейгельзимер, М.Б. Штерн // Физика и техника высоких давлений. - 2015. - Т. 25, № 3-4. C. $38-46$.

[15] Бейгельзимер Я.Е. Получение неспеченных гетерогенных композиционных материалов методом винтовой экструзии / Я.Е. Бейгельзимер, М.Б. Штерн, Т.А. Епифанцева и др. // Физика и техника высоких давлений. - 2009. - № 1/2. - С. 15-22.

[16] Павленко Д.В. Особенности уплотнения спеченных титановых сплавов методами обработки давлением / Д.В. Павленко // Обработка металлов давлением. 2017. - №1(44). - С. 174-180.

[17] Pavlenko D.V. Vortices in non-compact blanks during twist extrusion / D.V. Pavlenko. Ya.E. Beygelzimer // Powder Metallurgy and Metal Ceramics. - 2016. Vol. 54, Nos. 9-10. - P. 517-524.

[18] Beygelzimer Y. Vortices and mixing in metals during severe plastic deformation / Y.Beygelzimer// Mater. Sci. Forum. - 2011. - Vol. 683. - P. 213-224.

[19] Павленко Д.В. Повышение технологической пластичности спеченных титановых сплавов / Д.В. Павленко // 
Процеси механічної обробки в машинобудуванні. 2015. - Випуск 15. - С. 1-14.

[20] Тарасов А.Ф Совершенствование технологических процессов и оснастки для деформирования порошковых заготовок с применением интенсивной пластической деформации / А.Ф. Тарасов, Я.Ю. Бейгельзимер,
Д.В. Павленко, М.Б. Штерн // Обработка металлов давлением. 2015. - №2(41). - С. 336- 344 .

[21] Павленко Д.В. Методика оптимизации канала матриц для винтовой экструзии / Д.В. Павленко // Журнал инженерных наук. - 2015. - Т. 2. №1. C. $8-15$.

BoguslayezV. A ${ }^{1}$, Kotsyuba V. Yu. ${ }^{1}$, Pavlenko D. V. ${ }^{2}$

${ }^{1}$ Motor Sich, JSC. Ukraine, Zaporozhye

${ }^{2}$ Zaporozhye National Technical University. Ukraine, Zaporozhye

\section{MODERNIZATION OF THE MACHINE PRESSES FOR THE SAKE OF AVIATION ALLOYS SEVERE PLASTIC DEFORMATION TECHNOLOGIES IMPLEMENTATION}

The analysis of the peculiarities of severe plastic deformation of metals and alloys due to the twist extrusion is performed. The main requirements to the machine presses provides the severe plastic deformation technology due to the twist extrusion are considered. The basic principles and ways of modernization of the hydraulic presses for implementation of this technology in a batch production are developed. The problems of modernization of machine press control, hydraulic and electrical systems, as well as the work safety measures are solved. The example of the hydraulic press II-315 shows the ways of modernization of hydraulic presses, allowing deformation of blanks from a wide range of titanium and Fe-Ni alloys via twist extrusion on pilot equipment. [dx.doi.org/10.29010/081.1]

Keywords: hydraulic press; modernization; intensive-plastic deformation; twist extrusion; hydraulic system; electrical system; automation.

\section{References}

[1] Roberto B. Using Severe Plastic Deformation for the Processing of Advanced Engineering Materials / B. Roberto, I. Figueiredo, G. Terence, I. Angdoni // Materials Transactions. - 2009. - Vol. 50, No. 7 - P. 1613-1619.

[2] Greger M. Mechanical properties of ultra-fine in titanium / M. Greger, M. Widomska, L. Kander // Journal of Achievements in Materials and Manufacturing Engineering. - 2010. - Vol. 40, ISSUE 1, - P. 33-40.

[3] Valiev R. Z. A Paradox of Severe Plastic Deformation in Metals / R Z. Valiev, I.V. Aleksandrov // Doklady Physics. 2001. - Vol. 46, No. 9, - P. 633-635.

[4] Verlinden B. Sever plastic deformation of metals / B. Verlinden // Metalurgija - Journal of metallurgy. - 2005. - Vol.11 P. $165-182$.

[5] Wang Cheng Peng Review on modified and novel techniques of severe plastic deformation / W. Cheng Peng, L. FuGuo, W. Lei, Q. Huijuan // Technological Sciences. - 2012. - Vol.55 No.9: $\neg$ P. 2377-2390.

[6] Kolesnikov A.G. Analiz sposobov izmel'chenija struktury pri poluchenii metallicheskih konstrukcionnyh materialov / A.G. Kolesnikov., A.S. Shinkarev. // Nauka i Obrazovanie. MGTU im. N.Je. Baumana. Jelektron. Zhurnal. - 2014. № 11. - S. 34-44.

[7] Valiev R. Z. Producing Bulk Ultrafine-Grained Materials by Severe Plastic Deformation: Ten Years Later / R. Z. Valiev, Y. Estrin, Z. Horita at at. // Journal of the materials. - 2016. - Vol. 68, No. 4. - P. 1216-1226.

[8] Sabirov I. Nanostructure aluminum alloys produced by severe plastic deformation: new horizons in development / I. Sabirov, M.Yu. Murashkin, R.Z. Valiev // Materials Science \& Engineering. - 2013. -Vol. 560, - P. 1-24.

[9] Beygelzimer Y Twist Extrusion as a Potent Tool for Obtaining Advanced Engineering Materials: A Review / Y. Beygelzimer, R. Kulagin, Y. Estrin, at. al // Advanced engineering materials. - 2017. - Vol. 19, Issue 8. - P 1600873.

[10] Sergeev S.N. Vlijanie vsestoronnej izotermicheskoj kovki na strukturu i svojstva nizkouglerodistoj stali 12GBA / S.N. Sergeev, I.M. Safarov, A.V. Korznikovi dr. // Pis'ma o materialah. - 2012. - T.2 - S. 117-120. 
[11] Tarasov A.F. Razvitie kombinirovannyh metodov obrabotki s ispol'zovaniem intensivnogo plasticheskogo deformirovanija / A.F. Tarasov A.V. Altuhov, O.S. Litvin // Plastichna deformacija metaliv. - 2017. - S. 282 - 288.

[12] Pavlenko D.V. Metodologija obrabotki davleniem spechennyh splavov pri izgotovlenii detalejgazoturbinnyh dvigatelej / D.V. Pavlenko // Vestnik dvigatelestroenija. - 2017. - №1. - S. 83-92.

[13] Pavlenko D.V. Analiz uslovij formirovanija submikrokristallicheskoj struktury v zhelezonikelevyh splavah vintovoj jekstruziej / D.V. Pavlenko, D.V. Tkach, V.Ju. Kocjuba, Ja.E. Bejgel'zimer // Metallovedenie I termicheskaja obrabotka metallov. - 2017. - №5. - S. 8-14.

[14] Mihajlov O.V. Modelirovanie processa vintovoj jekstruzii poroshkovyh zagotovok / O.V. Mihajlov, Ja.E. Bejgelzimer, M.B. Shtern // Fizika I tehnika vysokih davlenij. - 2015, T. 25, № 3-4. - S. 38-46.

[15] Bejgelzimer Ja.E. Poluchenie nespechennyh geterogennyh kompozicionnyh materialov metodom vintovoj jekstruzii / Ja.E. Bejgel'zimer, M.B. Shtern., T.A. Epifancevai dr. // Fizika I tehnika vysokih davlenij. - 2009. - № 1/2 - C. 15-22.

[16] Pavlenko D.V. Osobennosti uplotnenija spechennyh titanovyh splavov metodami obrabotki davleniem / D.V. Pavlenko //Obrabotka metallov davleniem. - 2017. - №1(44) S.174-180.

[17] Pavlenko D.V. Vortices in non-compact blanks during twist extrusion / D.V. Pavlenko. Ya.E. Beygelzimer// Powder Metallurgy and Metal Ceramics. - 2016. - Vol. 54, Nos. 9-10, - P. 517-524.

[18] Beygelzimer Y. Vortices and mixing in metals during severe plastic deformation/ Y. Beygelzimer// Mater. Sci. Forum. 2011. - Vol. 683. - P. 213-224.

[19] Pavlenko D.V. Povyshenie tehnologicheskoj plastichnosti spechennyh titanovyh splavov / D.V. Pavlenko // Procesi mehanichnoï obrobki v mashinobuduvanni. - 2015. - Vipusk 15. - S. 1 - 14.

[20] Tarasov A.F. Sovershenstvovanie tehnologicheskih processov I osnastki dlja deformirovanijaporoshkovyh zagotovok s primeneniem intensivnoj plasticheskoj deformacii / A.F. Tarasov, Ja.Ju. Bejgel'zimer, D.V. Pavlenko, M.B. Shtern //Obrabotka metallov davleniem. - 2015. - №2(41). - S. 336-344.

[21] Pavlenko D.V. Metodika optimizacii kanala matric dlja vintovoj jekstruzii / D.V. Pavlenko // Zhurnal inzhenernyh nauk. 2015. - T. 2. № 1. - S. 8-15. 